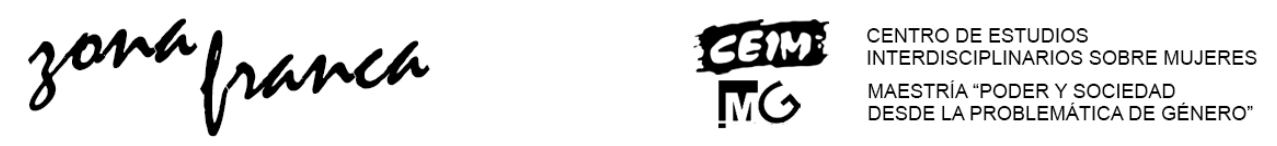

\title{
Aportes del feminismo al trabajo social \\ ¿qué significa pensar un trabajo social feminista?
}

Lorena María Guzzetti ${ }^{*}$ Antonella Margot Bouza ${ }^{* *}$ Florencia Ovando*** Carolina

Rabasa Rucki***

\section{Resumen}

En el presente artículo se presentarán algunos aportes conceptuales que consideramos fundamentales para construir una práctica profesional del trabajo social feminista. Para esto, reflexionaremos sobre la feminización de la disciplina y sus inicios como profesión, Posteriormente nos detendremos en dos herramientas de la disciplina sobre las cuales nos interesa incorporar una mirada que identifique las opresiones de género: la intervención social en los espacios grupales y el abordaje interdisciplinar.

Para el desarrollo argumentativo de esta propuesta de trabajo se incorporarán conceptualizaciones feministas y corpus teórico metodológico del quehacer profesional.

Palabras claves: Trabajo social- Feminismo- Intervención

Contributions from feminism to Social Work

\section{¿What does it mean to think about a Feminist Social Work?}

*Carrera de Trabajo Social. Universidad de Buenos Aires. Contacto: lorenamguzzetti@gmail.com

** Carrera de Trabajo Social. Universidad de Buenos Aires. Contacto: antonella.bouza@gmail.com

*** Carrera de Trabajo Social. Universidad de Buenos Aires.

Contacto:florenciaovando@hotmail.com

**** Carrera de Trabajo Social. Universidad de Buenos Aires. Contacto: carolinarabasa@gmail.com

Guzzetti, Lorena María; Bouza, Antonella Margot; Ovando, Florencia; Rabasa Rucki, Carolina. "Aportes del feminismo al trabajo social ¿qué significa pensar un trabajo social feminista?" en Zona Franca. Revista del Centro de estudios Interdisciplinario sobre las Mujeres, y de la Maestría poder y sociedad desde la problemática de Género, №27, 2019 pp.16-35. ISSN, 2545-6504 Recibido: 30 de junio 2019; Aceptado: 23 de noviembre 2019

Revista Zona Franca- Centro de estudios interdisciplinario sobre las mujeres (CEIM)- Maestría poder y sociedad desde la problemática de género (MG), Rosario, Argentina. ISSN, 2545-6504 http://zonafranca.unr.edu.ar/index.php/ZonaFrancal Numero 27 (2019).

Página 16 


\section{Abstract}

In the present article there will be introduced some conceptual contributions which we believe are essential to construct the professional practice of a feminist social work. In order to do this, we will first reflect upon the feminization of the discipline and its origins as a profession. In the second place, we will attend two support tools of the discipline, upon which we are interested to incorporate a perspective that identifies gender oppressions: social intervention inside groupal spaces and the interdisciplinary approach.

For the argumentative development of this work proposal there will be incorporated feminist conceptualizations and theoretical methodological corpus of the professional work.

Key words: Social Work - Feminism - Intervention

\section{Introducción}

El propósito de este artículo es presentar algunos aportes al debate y la construcción del ejercicio de un trabajo social feminista de manera crítica, y estableciendo vinculaciones entre los conceptos que consideramos son los destacados para esta tarea.

Para esto, entendemos que es relevante acercarnos a la comprensión de la caracterizada feminización de la profesión, tanto en su trayectoria histórica como en su impacto actual sobre el ejercicio de las prácticas profesionales.

Para esto, recurriremos a lo que comprendemos como conceptos claves como la perspectiva de género, patriarcado, heteronormatividad, que nos han permitido el reconocimiento de diferentes opresiones que se presentan a diario en nuestros espacios de inserción pre-profesional y profesional. Asimismo, estas opresiones cristalizadas en la cotidianeidad, son recuperadas teóricamente para amalgamarlas con la propuesta política-metodológica del trabajo social.

Luego, articulamos el trabajo grupal como una herramienta fundamental para la disciplina, y la importancia de abordar este nivel de intervención desde un trabajo social feminista.

Revista Zona Franca- Centro de estudios interdisciplinario sobre las mujeres (CEIM)- Maestría poder y sociedad desde la problemática de género (MG), Rosario, Argentina. ISSN, 2545-6504 http://zonafranca.unr.edu.ar/index.php/ZonaFrancal Numero 27 (2019). 
Finalmente, propondremos un conjunto de aportes para el trabajo interdisciplinario que ofrece un trabajo social feminista. Una mirada integral sobre nuestras prácticas, que resignifique nuestro bagaje teórico conceptual a la luz de las teorías y conceptos acuñados por el feminismo, es un desafío constante que nos interesa asumir. Así como también, habilitar encuentros entre la militancia activa del movimiento feminista y las aulas de nuestra facultad.

Cuando hablamos de feminismo, entendemos que son los feminismos, asumiendo que un movimiento expresa múltiples expresiones y posicionamientos político - ideológicos.

De esta forma nació este artículo, como un encuentro reflexivo entre activismo y espacios reflexivos y entusiastas, entre docentes y estudiantes.

\section{Feminización y Trabajo Social}

Consideramos relevante destacar, que fueron mujeres en Estados Unidos, en el siglo XIX (las primeras universitarias de su época) las que construyeron la profesionalización de la disciplina. Varias de ellas ("las pioneras") fueron vanguardia en la lucha por los derechos de las mujeres y militantes de diversas causas sociales: sufragistas, pacifistas, abolicionistas de la esclavitud. Eran en su mayoría integrantes del Movimiento Reformista y de las luchas emancipadoras de la época. Necesitamos contextualizar y realizar las interpretaciones y nexos que nos permitan analizar el lugar que ocupaba ese colectivo que elaboró los cimientos para incorporar la disciplina en las Ciencias Sociales.

También, una de las características de la configuración de la profesión fueron las mujeres que desarrollaban tareas en el ámbito de la beneficencia. Haciendo referencia a nuestro país y la Sociedad de Beneficencia, nos señala Dora Barrancos,

\footnotetext{
"Las mujeres de la Asociación disfrutaban de una situación que, aunque subrrogante de las potestades masculinas en lo esencial, no carecía de
}

Revista Zona Franca- Centro de estudios interdisciplinario sobre las mujeres (CEIM)- Maestría poder y sociedad desde la problemática de género (MG), Rosario, Argentina. ISSN, 2545-6504 http://zonafranca.unr.edu.ar/index.php/ZonaFrancal Numero 27 (2019). 
decisiones independientes que las llevaron a momentos de alta tensión con los poderes del Estado y, como ya he señalado, con el expansivo sector de los profesionales médicos que disputaban hegemonía." (Barrancos, 2005).

Agrega, Genolet, haciendo referencia a los orígenes de la profesión en nuestro país que

“...comienzan a configurar su intervención en un contexto de cambio del rol del estado y de las políticas sociales. Estamos en los albores del estado de bienestar donde éste asume bajo su responsabilidad la asistencia social, creando estructuras institucionales vigorosas para atender la pobreza y la salud de la población" (Genolet, 2011:91).

Siguiendo a Grassi (1989), podemos afirmar que las mujeres históricamente han tenido una acción relacionada al control y a la vida cotidiana, tanto desde sus papeles al interior del hogar (como objetos de intervención), como desde la función pública (agentes de control), naturalizados como hechos fundados. De alguna manera, el inicio de la asistencia social se explica por su rol en la legitimidad y el consenso, en el control de la vida cotidiana. Así es, que se explica la presencia mayoritaria de mujeres, ligado a un perfil profesional enmarcado a "a lo afectivo".

Pero dentro de ese marco general, la asistencia social se dirige a un ámbito particular de la vida de les sujetes, en el cual crea un orden, una disciplina: el ámbito de la vida cotidiana. En este sentido, coincidimos con Grassi (1989) en que el poder político del Estado trasciende aquello que podemos llamar "lo público", para imbricarse con el espacio "privado".

De esta forma, es posible identificar dos características fundantes que moldearon la profesión desde su origen: primero, su lugar desde la función pública, y segundo, ligado a lo anterior, ejercida mayoritariamente por las mujeres. Es en esas circunstancias donde las mujeres se constituyen en centro ordenador,

Revista Zona Franca- Centro de estudios interdisciplinario sobre las mujeres (CEIM)- Maestría poder y sociedad desde la problemática de género (MG), Rosario, Argentina. ISSN, 2545-6504 http://zonafranca.unr.edu.ar/index.php/ZonaFrancal Numero 27 (2019). 
para lo cual han internalizado una serie de características que, aprendidas culturalmente, "naturalizan", sin embargo, su función.

Esto sin dudas nos lleva a preguntarnos por el lugar que fue ocupando la profesión, que comenzó estando "al servicio de", y que luego construyó su corpus teórico y su especificidad. En ese marco, ¿es el trabajo social una profesión subestimada porque está fundamentalmente compuesta por un colectivo profesional de mujeres? ¿O es que las mujeres (por ser mujeres) indefectiblemente deben asumir disciplinas "con prácticas vinculadas al cuidado" como el trabajo social?

Sin dudas, es un interrogante que no podemos responder en el marco de este trabajo, pero esta pregunta nos motiva a pensar acerca de las conexiones olvidadas y, por sobre todo, invisibles que operan a lo largo de la historia.

Creemos que es necesario problematizar la fuerte impronta "femenina" que tiene el Trabajo Social como disciplina. Algunas autoras feministas plantean que "esto es consecuencia de la problematización del trabajo social oficial como institución social que refuerza la posición subordinada de las mujeres" (Dominelli y Mac Leod, 1999:44). El motivo dominante en la práctica institucional ha sido el de reforzar el rol de las mujeres como proveedoras de asistencia.

Retomando la relación entre mundo público y mundo privado, es un aporte fundamental de las teorías de género y el feminismo el análisis de las transformaciones que estos espacios han transitado a lo largo de la historia. Así como también, se visibilizó la construcción moderna de esta división social. Escribe Ana María Fernández, "espacio público-privado: no solo división de tareas sino prohibición de tareas según el sexo; por lo tanto, habrá que articular la indagación de esta cuestión con su dimensión política, es decir, con aquellos problemas vinculados a las relaciones de poder..." (Fernández, 1999:134). Para cada uno de estos espacios se diagramaron funciones discriminadas, códigos propios y con formas diferenciadas en la circulación de saberes. Esta división

Revista Zona Franca- Centro de estudios interdisciplinario sobre las mujeres (CEIM)- Maestría poder y sociedad desde la problemática de género (MG), Rosario, Argentina. ISSN, 2545-6504 http://zonafranca.unr.edu.ar/index.php/ZonaFranca| Numero 27 (2019). 
sexual del trabajo ubica a las mujeres como responsables de las tareas de cuidado (en el mundo privado), asumiendo que "se debe estar a disposición del bienestar de los demás". Es que al fin y al cabo, eso es lo que el sistema-sexo género nos ha impuesto: las mujeres y todos los cuerpos feminizados deben estar al servicio de los demás, de las infancias, de las personas ancianas, de les enfermes, de todes las personas que necesiten asistencia y/o algún cuidado en particular. Y a su vez, tal como explica Murillo (2006), es en este espacio privado donde la actividad doméstica devalúa a quien la ejerce, ya que la importancia de esta es negada por la irracionabilidad social. En este sentido, no resulta casual que en su mayoría sean mujeres las profesionales que componen el recurso humano de la profesión. Y es aún menos casual, entonces, que el Trabajo Social esté inherentemente relacionado con atributos femeninos, y con ésta condición de género que feminiza constantemente la profesión y reproduce los estereotipos de carácter "asistencial", subalternizándola en tanto disciplina científica, subestimándola y relegándola a una profesión auxiliar respecto de otras profesiones.

La organización del sistema patriarcal y la complejidad social en una sociedad que oprime a las mujeres y los cuerpos disidentes tanto en planos materiales como simbólicos, afecta y atraviesa integralmente nuestras identidades, entre otras cosas: nuestro ejercicio profesional.

A su vez, es necesaria una constante interpelación a nivel simbólico de nuestra perspectiva para analizar el campo social y las relaciones de poder que lo componen y sobre el cual se interviene. En este sentido, las intervenciones sociales son imposibles de ser pensadas si no es a la luz de la historicidad de las relaciones de poder. Intervención que debe incluir en su aproximación diagnóstica inicial la lectura de los procesos sociales y las construcciones de subalternidades que de allí devienen.

Revista Zona Franca- Centro de estudios interdisciplinario sobre las mujeres (CEIM)- Maestría poder y sociedad desde la problemática de género (MG), Rosario, Argentina. ISSN, 2545-6504 http://zonafranca.unr.edu.ar/index.php/ZonaFranca| Numero 27 (2019). 
Asimismo, la violencia vincula el accionar de las instituciones con la más íntima conformación de las personas. La violencia simbólica que se manifiesta a través de las instituciones regula todo tipo de intercambio y producción social. El miedo, proporciona el mecanismo central para la introyección de los controles sociales y la regulación autoadministrada de todo aquel comportamiento (Basaglia, 1972:20) que se escape de lo socialmente atribuido al "ser un cuerpo feminizado". De esta forma, las profesionales corremos el riesgo de reproducir con nuestras acciones determinados comportamientos mecanicistas y poco desnaturalizados que refuerzan la subalternización de la profesión, porque es lo que "se espera de nosotras/es".

Bajo este panorama cabe preguntarnos ¿Cómo se configura, entonces, el quehacer profesional específico del Trabajo Social feminista en una sociedad como la nuestra, neoliberal y patriarcal?

\section{Conceptos que nos acompañan}

Algunas definiciones son claves para comprender el desafío de incorporar una mirada feminista y analizar nuestras prácticas profesionales.

El concepto de patriarcado fue acuñado por los movimientos feministas "para establecer la cuestión de la base real de la subordinación de las mujeres, y para analizar las formas particulares que asume" (Beechey, 1979:1). Sin embargo, cuenta con múltiples definiciones, desarrolladas a partir de diferentes perspectivas teóricas a través del tiempo. Una autora que define dicho concepto es Carosio (2016), quien lo entiende como:

"un sistema socio-político y económico que organiza el trabajo, y el poder según el modelo masculino (...) todo lo masculino tiene más valoración social, y abre más horizontes con mayor facilidad, se justifica y legitima la dominación sobre la base de una supuesta inferioridad (biológica y/o psicológica) de las mujeres, por lo tanto, el patriarcado es también un sistema ideológico" (Carosio, 2016:249).

Revista Zona Franca- Centro de estudios interdisciplinario sobre las mujeres (CEIM)- Maestría poder y sociedad desde la problemática de género (MG), Rosario, Argentina. ISSN, 2545-6504 http://zonafranca.unr.edu.ar/index.php/ZonaFrancal Numero 27 (2019). 
Este sistema ha sido sostenido a lo largo de milenios, sin embargo sus características han variado de sociedad en sociedad. Adicionalmente, al interior de las mismas sociedades, es posible observar que sus disposiciones han sido modificadas, pero descritas como naturales a través de valores, representaciones y creencias articuladas en el interior de un sistema simbólico, y constituyendo condiciones materiales. Asimismo, el patriarcado se cristaliza en procesos de institucionalización complejos y estructurales.

Desde sus inicios, el patriarcado ha definido lugares que incluyen y excluyen a cada persona, entendiendo que el ámbito privado les es asignado a las mujeres, y el ámbito público a los varones. Esta conformación estructural de la organización social, excluye a las mujeres y cuerpos feminizados de la idea de ciudadanía plena. Dicha división contrapuesta de los espacios se expresa en cada una de las instituciones con las que interactuamos a diario y en las que nos encontramos incluidas profesionalmente. Las demandas de las mujeres y de otros grupos por la igualdad, por el acceso a los espacios públicos, a los mecanismos políticos decisorios de nuestra cotidianidad y a los bienes materiales, es un extenso recorrido de carácter emancipatorio por el reconocimiento y la redistribución social en tanto sujetos autónomos.

Como resultado de las luchas feministas, las modificaciones de las aspiraciones sociales han ido reconfigurando las expresiones materiales de las relaciones de dominación, sin embargo, su núcleo basado en la supuesta superioridad masculina permanece. El patriarcado es un sistema socialmente determinado de relaciones duraderas que establece resistencias frente a los intentos de socavarlo.

Marcela Lagarde (2001) define a la perspectiva de género feminista como aquella que "está basada en la teoría de género y se inscribe en el paradigma teórico histórico-crítico y en el paradigma cultural del feminismo" (p. 13). Cada sociedad regula los cuerpos según su diferencia anatómica, adjudicando

Revista Zona Franca- Centro de estudios interdisciplinario sobre las mujeres (CEIM)- Maestría poder y sociedad desde la problemática de género (MG), Rosario, Argentina. ISSN, 2545-6504 http://zonafranca.unr.edu.ar/index.php/ZonaFrancal Numero 27 (2019). 
características propias a cada uno de estos. La categoría de género nos permite cuestionar estas construcciones estereotipadas que definen y naturalizan los comportamientos de las personas, manteniendo relaciones de poder que generan y promueven múltiples formas de violencia y actos discriminatorios hacia las mujeres y cuerpos disidentes.

Asimismo, Joan Scott (1996) establece que el género es una forma primaria de significantes de poder. Es decir, es un campo donde se articula y disputa el poder, hasta el punto en que esas referencias establecen distribuciones de poder (control diferencial sobre los recursos materiales y simbólicos, o acceso a los mismos), estando el género implicado en la concepción y construcción del poder.

Estas subordinaciones que se generan desde, y por las desigualdades de género, son una cuestión de poder que no se ubica solamente en las instituciones, sino que se extiende y que se localiza en los diferentes espacios sociales. En este sentido, incorporamos (sin extendernos en su desarrollo en este artículo) el concepto de heteronormatividad, como instrumento teórico que problematiza las normas de género, y la existencia legítima y hegemónica de la naturalidad de la heterosexualidad.

Es necesario desentrañar cada una de estas categorías en los espacios sociales, en las prácticas, en la transmisión de sentidos, en las representaciones que integran el sistema sexo/género, en clave de reconocimiento y de desigualdad social. Entendemos, como lo hace Fraser (2015) que el concepto de género debe incorporar la concepción bidimensional, es decir, una cara política-económica que lo incluye en el ámbito de la redistribución, y una cara cultural que lo incluye simultáneamente en el ámbito del reconocimiento (status social). Ambas dimensiones se encuentran interconectadas y no es posible modificar una sin afectar a la otra.

El movimiento feminista ha sido clave en la interpelación de la realidad social, la producción de conocimiento teórico sobre las desigualdades de género, y

Revista Zona Franca- Centro de estudios interdisciplinario sobre las mujeres (CEIM)- Maestría poder y sociedad desde la problemática de género (MG), Rosario, Argentina. ISSN, 2545-6504 http://zonafranca.unr.edu.ar/index.php/ZonaFranca| Numero 27 (2019). 
la movilización de apoyo a acciones concretas para la modificación de las condiciones sociales de producción y reproducción de la vida.

Desde allí que Lagarde (2012) sostiene que el feminismo ha utilizado

"la crítica, la rebeldía, la subversión, la transgresión creadora y la construcción de alternativas paradigmáticas. Ha creado rupturas sustantivas con la vida social moderna tan profundas que cimientan un nuevo paradigma civilizatorio basado a su vez en un nuevo paradigma de género en proceso" (p. 306).

Entendemos a los feminismos como un pensamiento crítico contrahegemónico y movimiento emancipador que se propone finalizar con las formas de opresión patriarcales. En palabras de Carosio,

\begin{abstract}
"a partir del desvelamiento de la construcción social de las identidades sexuadas, el feminismo elabora una teoría de las relaciones de poder entre los sexos y con una voluntad ética y política de denuncia de las deformaciones conceptuales de un discurso hegemónico basado en la exclusión e inferiorización de la mitad de la especie humana." (Carosio, 2016: 248)
\end{abstract}

El feminismo se ha caracterizado por proponer un modelo de sociedad alternativa a la sociedad patriarcal vigente, y someter inclusive el término "género" a una revisión y construcción constante. Las agendas y el discurrir de la militancia feminista nos brindan conceptos y herramientas de una lucidez develadora para la comprensión y transformación de los sistemas de producción de opresiones.

Sin ahondar en este artículo, quisiéramos recuperar para profundizar el análisis la categoría de interseccionalidad en relación a la presencia de dobles o triples opresiones y los sistemas y prácticas que las reproducen.

Como explica Fraser (2015:191), es necesario romper con los enfoques feministas que se centran exclusivamente en el género, para situar "las luchas de género, por el contrario, como una rama entre otras de un proyecto político más

Revista Zona Franca- Centro de estudios interdisciplinario sobre las mujeres (CEIM)- Maestría poder y sociedad desde la problemática de género (MG), Rosario, Argentina. ISSN, 2545-6504 http://zonafranca.unr.edu.ar/index.php/ZonaFrancal Numero 27 (2019). 
amplio dirigido a institucionalizar la justicia democrática en múltiples ejes de diferenciación social”.

En síntesis, la mirada feminista también logra trascender la lógica de la individualidad para pensar en una organización desde la grupalidad. De allí la importancia de poder pensar desde el Trabajo Social, una forma de intervención promovida por el feminismo, en el trabajo con grupos.

\section{Acontecer en la grupalidad}

En un segundo momento, con los elementos proporcionados por los feminismos, es necesario dar cuenta de la importancia del trabajo con grupos como nivel de intervención dentro del Trabajo Social. Entendemos que el espacio grupal "es la forma más eficaz para promover cambios en las actitudes, conductas, emociones y hábitos, a través de la reflexión conjunta, el intercambio de experiencias, el autoconocimiento, la autovaloración y apoyo mutuo" (Migallón y Gálvez: 1999).

El grupo, así concebido, se convierte en una herramienta que brinda las condiciones de posibilidad para recorrer un proceso de aprendizaje dentro de un colectivo. Dicho espacio está pensado para potenciar a cada integrante, lograr una comunicación plena entre les participantes, reparar vínculos y redes, conformando así un proceso superador.

De esta forma, el grupo se torna una herramienta de intervención crucial dado que también permite visibilizar mitos, valores, y representaciones patriarcales. Es que por medio de diversos grupos sociales, una sociedad transmite, perpetua, y modifica sus normas, sus valores y sus rasgos culturales. También a través de ellos, las personas actúan y participan de la vida social: "La vida de un grupo está directamente influida por las normas y valores mayoritariamente admitidos en su campo de inserción, así como por el grado de tolerancia en cuanto a la desviación de la norma" (De Robertis y Pascal,

Revista Zona Franca- Centro de estudios interdisciplinario sobre las mujeres (CEIM)- Maestría poder y sociedad desde la problemática de género (MG), Rosario, Argentina. ISSN, 2545-6504 http://zonafranca.unr.edu.ar/index.php/ZonaFranca| Numero 27 (2019). 
2007:195). Por ello, los grupos son un espacio fundamental para visibilizar las implicancias de la perspectiva de género feminista como herramienta de intervención social.

Sin embargo, desde el rol profesional es necesario reconocer que al interior de los grupos, se parte de una relación que está absolutamente atravesada por diferentes tipos de desigualdades que colocan en diferentes posiciones a la coordinación y a les participantes. La desigualdad de género se convierte en ese marco, en una de las más invisibles, pero que resulta inherente a nuestra sociedad patriarcal. Por esto, se torna clave incluir al interior de la planificación y ejecución de una intervención grupal desde la perspectiva de género feminista, aspectos que nos permitan indagar acerca del complejo entramado de relaciones interpersonales, institucionales y sociales, para construir objetivos comunes expresados en la tarea.

Este tipo de lectura debe ser desplegada indefectiblemente desde el rol profesional durante las intervenciones, junto con un proceso constante de reflexividad en cuanto a las propias prácticas, para identificar y sortear las ideas y comportamientos machistas interiorizados que podrían obstruir los objetivos de la intervención. Solo así, la intervención con grupos apuntará a fortalecer la autoestima, contener ansiedades, esclarecer significados, aportar información y conocimientos, ampliar la comprensión de sujete situade en un marco más amplio de inequidad (distributiva, material, simbólica), como también a visibilizar y generar la desnaturalización de las lógicas normativas de género.

La conformación de grupos, en nuestra tarea profesional, implica un compromiso con una modalidad de construcción política que encuentra en ese ámbito un espacio para deconstruir-nos, situado en un contexto sociopolítico determinado. En tanto, el grupo no es estático, el acontecer grupal vivencia de forma dialéctica su movimiento inacabado.

Revista Zona Franca- Centro de estudios interdisciplinario sobre las mujeres (CEIM)- Maestría poder y sociedad desde la problemática de género (MG), Rosario, Argentina. ISSN, 2545-6504 http://zonafranca.unr.edu.ar/index.php/ZonaFranca| Numero 27 (2019). 
Bajo este posicionamiento político, dentro de los grupos, lo privado también se convierte en algo social y, a la vez, posibilita romper con esa barrera de invisibilización que coloca lo privado y lo público como dos cosas separadas por fuera de lo político. El foco sobre el trabajo reflexivo y colectivo, promoviendo la circulación de experiencias personales para "encontrarse en la otra persona" es fundamental para sacar del plano individual lo que es en realidad un problema social. En este sentido, siguiendo a Murillo (2006), resulta clave utilizar estos espacios de intercambio para replantear - y replantearnos- la distribución de las responsabilidades del ámbito privado.

\section{Trabajadoras sociales feministas en los equipos interdisciplinarios}

Hemos mencionado ya la particularidad y la riqueza de los grupos como herramientas de intervención. Sin embargo, creer que naturalmente el curso de la interacción se daría de esa forma sería desconocer las implicancias de la intervención de los equipos que la llevan a cabo. Olga Vélez Restrepo (2003), señala que les profesionales intervinientes deben ser quienes construyan un instrumental que recoja los sentidos y necesidades de les actores involucrades y aporten a la construcción del conocimiento y configuración de les sujetos sociales. En este sentido, es que planteamos que trabajar en torno a las desigualdades estructurales de género al interior de las dinámicas grupales, es una tarea que se ve enriquecida por la acción de equipos interdisciplinarios.

La interdisciplina, es entendida como un campo compartido con otres profesionales y como una herramienta fundamental para intervenir en lo social que permite dar respuestas a la multiplicidad de demandas y las problemáticas sociales actuales (Cazzaniga, 2002).

Siguiendo a Stolkiner (1999), se puede considerar dos aspectos relevantes de lo interdisciplinar: lo subjetivo y lo grupal. Ambos se encuentran íntimamente relacionados ya que los equipos interdisciplinarios son grupos que contemplan lo

Revista Zona Franca- Centro de estudios interdisciplinario sobre las mujeres (CEIM)- Maestría poder y sociedad desde la problemática de género (MG), Rosario, Argentina. ISSN, 2545-6504 http://zonafranca.unr.edu.ar/index.php/ZonaFranca| Numero 27 (2019). 
subjetivo y lo intersubjetivo, y a la vez, están atravesados por relaciones de poder. Es necesario renunciar al saber propio disciplinar para dar lugar a otros saberes, y poder ampliar horizontes en lo que respecta a los conocimientos, ya que como plantea la autora "toda relación con una disciplina es pasional: podemos someternos a ella, refugiarnos en ella, o hacerla trabajar, desafiarla" (Stolkiner, 1999: 2).

En este sentido, es necesario buscar incorporar a los equipos de trabajo interdisciplinarios herramientas y conceptos de las teorías feministas, para tender a crear nuevos desafíos en lo que respecta a las formas de vincularse, jerarquizarse e intervenir. Y desde este análisis teórico, proponer la generación de singularidades con sentido propio a partir de los universos de significaciones de cada disciplina. Desnaturalizar y deconstruir las lógicas de formación y ordenamiento de cada campo de conocimiento, sin invalidar los recorridos y los aportes, es un desafío que busca un salto cualitativo para pensar las intervenciones.

La tarea de descentrar los objetos de estudios, conectar las problemáticas sociales e interconectar teorías y conceptos que operen articuladamente, nos permitirá abordar esos escenarios complejos de intervención con una multiplicidad de miradas y saberes; entre estas, las del feminismo. Asimismo, este desarrollo nos permitirá elaborar herramientas metodológicas que encuentren una relación entre las dimensiones sociales, culturales, económicas, políticas e ideológicas. La importancia de reconocer esta multiplicidad de aspectos presentes en una situación de intervención, es posible con el análisis de una mirada multidimensional e interdisciplinaria en el sentido que proponemos. Se trata de pensar desde la problematización permanente y la pregunta constante sobre las prácticas, entendiendo a las experiencias no como instituidas sino como posibilidades.

Revista Zona Franca- Centro de estudios interdisciplinario sobre las mujeres (CEIM)- Maestría poder y sociedad desde la problemática de género (MG), Rosario, Argentina. ISSN, 2545-6504 http://zonafranca.unr.edu.ar/index.php/ZonaFranca| Numero 27 (2019). 
Esto nos conduce a cuestionar certezas establecidas y/o dogmáticas, e indagar sobre las tensiones que se encuentran invisibilizadas en el espacio de acción profesional, haciéndolas visibles para leerlas interdisciplinariamente. En palabras de Fernández (2007: 30), se trata de "pensar problemas, más que aplicar sistemas teóricos".

Los aportes de trabajo social al trabajo interdisciplinario, implica brindar nuestros conocimientos acerca de la elaboración de una primera aproximación diagnóstica inicial que incluya el análisis de la demanda desde donde partimos para elaborar conjuntamente una estrategia de intervención. Estos aportes deben partir de los principios de los derechos de las personas (sujetes con potencialidades), entendidas como parte de un entramado social, y sobre el cual hay que definir acciones. El trabajo social, aporta una lectura sobre los procesos sociales recuperando las trayectorias singulares, que nutren los análisis de las situaciones problemáticas en torno a las políticas públicas.

En este sentido, consideramos al feminismo/los feminismos, como proyecto político, que tiene como horizonte la creación de relaciones horizontales y transversales, tanto al interior de los equipos interdisciplinarios, como al momento de la intervención mediante relaciones de paridad.

El patriarcado como construcción de sentido que permea nuestra vida y nuestra historia, está tan arraigado dentro nuestro que aun cuando se es consciente de su existencia y se trabaja por y para desarticular el discurso machista, hay determinados elementos tan incorporados en nuestros habitus que hacen que naturalicemos actitudes que nos fueron impuestas social, cultural, política, económica y, sobretodo, simbólicamente. Por ello, estar constantemente revisando nuestros preconceptos y puntos de partida es fundamental para visibilizar y objetivar nuestras propias construcciones permeadas por la desigualdad estructural. 
Por último, creemos que todos los aportes del feminismo y los feminismos no podrían llevarse a cabo sino mediante una construcción colectiva del conocimiento. La lucha por la liberación de les oprimides requiere de un proceso de reflexión que produzca conciencia de la opresión, mediante su inserción crítica en esta realidad. El reconocimiento de la realidad, no significa una acción transformadora en sí misma, sino que requiere de un reconocimiento reflexivo. En tanto, desde el rol profesional necesariamente las personas son "cuerpos conscientes" con posibilidades potenciales de problematizar su relación con el mundo.

Los equipos interdisciplinarios deben presentar un contenido disponible de ser admirado, para re-admirarlo juntes y reconfigurar nociones acerca de esa realidad. Las mujeres y los cuerpos feminizados, como principales oprimides de la sociedad patriarcal, se presentan como protagonistas de la lucha liberadora a través de los momentos de reflexividad y acción y de acción y reflexividad. Es un movimiento colectivo dialéctico con momentos de estancamiento, momentos disruptivos y momentos sumamente gratificantes.

\section{Reflexiones finales}

El Trabajo Social puede definirse como una profesión y una disciplina científica tendiente a promover y acompañar procesos de transformación en el campo social, propiciando la cohesión social y la liberación de las personas. Conforme lo establece el art. 4 de la Ley Federal de Trabajo Social № 27.072, de muy reciente sanción en nuestro país, los principios tales como la justicia social, derechos humanos y la diversidad en todas sus formas son esenciales para pensar la disciplina.

Pensar en un Trabajo Social Feminista implica la incorporación de un esfuerzo multifocal y colectivo, mediante un proceso de interpelación al interior de la disciplina, en su interjuego con otras disciplinas y, a su vez, en relación al

Revista Zona Franca- Centro de estudios interdisciplinario sobre las mujeres (CEIM)- Maestría poder y sociedad desde la problemática de género (MG), Rosario, Argentina. ISSN, 2545-6504 http://zonafranca.unr.edu.ar/index.php/ZonaFrancal Numero 27 (2019). 
desarrollo de su ejercicio profesional. Es así que entendemos que las miradas de los feminismos nos permiten revisarnos como profesión, revisar nuestro entorno y replantear nuestras prácticas, a partir de la comprensión de que todas estas instancias se encuentran atravesadas por la cuestión de género, presentando desigualdades que nos afectan como colectivo.

Al interior de la disciplina, hemos desarrollado en este artículo lo que consideramos se nos presenta una doble tarea. En primer lugar, visibilizar la feminización existente hacia adentro del Trabajo Social, y en sus orígenes. En segundo lugar, trabajar sobre el propio empoderamiento a nivel profesional para librarnos de las limitaciones que nos fueron adjudicadas en esta feminización. Es decir, poder proyectar las posibilidades de la profesión más allá de estas limitaciones, habilitándola desde su interior a la búsqueda de espacios de mayor autonomía y reconocimiento, y hacia la aspiración de posiciones de mayor impacto, por ejemplo, sobre la toma de decisiones y no solo su ejecución.

Esta perspectiva política - profesional posibilita la construcción y evaluación de estrategias de intervención social en espacios grupales. En este sentido, el andamiaje conceptual (referencias políticas y teóricas) nos permitirá reconocer nuestras intervenciones que se encuentren signadas por la reproducción de múltiples desigualdades (género, clase, etnia, etc.). Las intervenciones sociales no son asépticas a las contradicciones, es nuestro desafío interpelarlas, confrontarlas con nuestras teorías y preconceptos para re-descubrir sus potencialidades. Estas deben tener la capacidad de dar respuesta a los problemas sociales. Sin embargo, dicha respuesta sería acotada o parcial sin los aportes del feminismo, el cual como perspectiva de análisis y acción, contribuye a la desnaturalización de la desigualdad en que se desarrollan las relaciones de poder bajo el imperante sistema patriarcal.

Entendemos, que la perspectiva propuesta además de posibilitar una revisión interna, brinda herramientas para analizar las oportunidades de trabajo

Revista Zona Franca- Centro de estudios interdisciplinario sobre las mujeres (CEIM)- Maestría poder y sociedad desde la problemática de género (MG), Rosario, Argentina. ISSN, 2545-6504 http://zonafranca.unr.edu.ar/index.php/ZonaFranca| Numero 27 (2019). 
interdisciplinario recogiendo y reproduciendo las estrategias que utilizó el movimiento feminista para alcanzar un objetivo en común y enriquecer este proceso. En este sentido, es imperativo aunar esfuerzos para establecer espacios de horizontalidad, posibilitar relaciones articuladas entre las disciplinas, y replantear las formas de jerarquización. No basta con autopercibirnos como profesionales del Trabajo Social en condiciones de paridad respecto a las demás disciplinas, sino que es necesario ser reconocides como tales. Entendemos que este reconocimiento no opera sólo a nivel simbólico, sino que también implica alcanzar un mejoramiento de las condiciones laborales y materiales. Desnaturalizar y deconstruir las lógicas de formación y ordenamiento de cada campo de conocimiento es posible desde una mirada feminista, que funciona como herramienta para pensar la horizontalidad en los saberes compartidos, y construir relaciones al interior del ejercicio profesional y la interdisciplina. Esto no significa que no debamos asumir las tensiones que se presenten y los conflictos que se cristalicen.

En este marco, entendemos que los dos desafíos descritos hasta el momento, son inseparables de aquellos que enfrenta la lucha feminista, la cual busca romper con las posiciones desiguales en materia de género y visibilizar las múltiples opresiones.

Es por todo esto que entendemos que el trabajo social feminista es una propuesta de visibilización de los límites profesionales invisibilizados, de ruptura con relaciones disciplinares desiguales y de enriquecimiento de las intervenciones sociales que, en su complejidad, requieren de la incorporación de una perspectiva que reconozca y busque desnaturalizar la desigualdad de género mediante esfuerzos colectivos.

Es gratificante encontrar en las nuevas generaciones de estudiantes y grupos de profesionales, el impacto que les ha generado el movimiento feminista 
en los últimos años, acercando las preguntas, los intereses y el entusiasmo por construir un Trabajo Social feminista.

\section{Bibliografía}

BARRANCOS, Dora.(2005). Las mujeres y "su causa". http:/www.revistacriterio.com.ar/sociedad/lasmujeres-y-su-quotcausaquot/

CAZZANIGA, Susana. (2002) Trabajo e Interdisciplina: la cuestión de los equipos de salud en Revista Margen Edición №27. Primavera, Buenos Aires.

CAROSIO, Alba. (2016) Contribuciones del pensamiento feminista al pensamiento social, en Revista Latinoamericana de Investigación Crítica, Año III (N5), Julio-Diciembre 2016, P. 243-256. Buenos aires, Argentina: CLACSO.

BEECHEY, Verónica. (1979) Sobre el Patriarcado. En Feminist Review №3. (Trad. B. Ibarlucía y Mayra Lucio).

DELL'ANNO, Amelia. y TEUBAL, Ruth. (2006). Resignificando lo grupal en el Trabajo Social. Espacio Editorial, Buenos Aires.

DE ROBERTIS Cristina Y PASCAL Henri. (2007). Intervención colectiva en Trabajo Social. La acción con grupos y comunidades. Lumen, Buenos Aires.

DOMINELLI, Lena. y MAC LEOD, Heileen. (1999) "El comienzo de la intervención del trabajo social feminista: un enfoque feminista de la definición de los problemas sociales". En Trabajo Social feminista. Madrid: Cátedra.

FOUCAULT, Michel. (1992) Microfísica del poder. Madrid, España: La piqueta.

FERNÁNDEZ, Ana María. (1994). La Mujer de la ilusión. Paidós. Buenos Aires.

FERNÁNDEZ, Ana María. (2007) "Primera parte. Haciendo met-odhos". En

Las lógicas colectivas. Imaginarios, cuerpos y multiplicidades. Editorial Biblos. Buenos Aires.

FRASER, Nancy. (2015). Fortunas del feminismo. Traficantes de sueños. Madrid. 
GENOLET, Alicia (2011). "Configuración de los rasgos de identidad profesional y las intervenciones colectivas de los trabajadores sociales, a la luz de la mirada de género." En Ibañez Viviana (comp.), Historia, identidad e intervención profesional. Ediciones Suarez. Buenos Aires

GRASSI, Estela (1989). La mujer y la profesión de Asistente Social. El control de la vida cotidiana. Ed. Humanitas. Buenos Aires.

LAGARDE, Marcela.(1998) "Claves feministas para el poderío y autonomía de las mujeres". En Puntos de encuentro. Nicaragua.

LAGARDE, Marcela. (2009) "La política feminista de la sororidad". España. Mujeres en Red. El periódico feminista. Recuperado de http://www.mujeresenred.net/spip.php?article1771

MIGALLÓN, Pilar. y GÁLVEZ, Beatriz. (1999) Los grupos de mujeres, metodología y contenido para el trabajo grupal de la autoestima" Instituto de la Mujer, Madrid.

MURILLO, Soledad (2006). El mito de la vida privada. De la entrega al tiempo propio. Siglo XXI. España.

SEGATO, Rita (2004) Las estructuras elementales de la violencia. Ensayos sobre género entre la antropología, el psicoanálisis y los derechos humanos. Editorial Prometeo, Buenos Aires.

SCOTT, Joan (1986). "El género: una categoría útil para el análisis histórico". En Lamas, Marta. (Comp.) El Género: La construcción cultural de la diferencia sexual. México: PUEG, pp. 265-302

STOLKINER, Alicia. (1999) "La Interdisciplina: entre la epistemología y las prácticas". Revista El Campo Psi (10). Disponible en: http://www.campopsi.com.ar/lecturas/stolkiner.htm

LEY FEDERAL DE TRABAJO SOCIAL 27.072 Sancionada: Diciembre 10 de 2014 Promulgada: Diciembre 16 de 2014

Revista Zona Franca- Centro de estudios interdisciplinario sobre las mujeres (CEIM)- Maestría poder y sociedad desde la problemática de género (MG), Rosario, Argentina. ISSN, 2545-6504 http://zonafranca.unr.edu.ar/index.php/ZonaFranca| Numero 27 (2019). 